\title{
Correction to: Open-label pilot
}

(a) CrossMark for treatment targeting gut dysbiosis in myalgic encephalomyelitis/chronic fatigue syndrome: neuropsychological symptoms and sex comparisons

Amy Wallis ${ }^{1 *} \mathbb{0}$, Michelle Ball ${ }^{1}$, Henry Butt ${ }^{2}$, Donald P. Lewis ${ }^{3}$, Sandra McKechnie ${ }^{4}$, Phillip Paull ${ }^{2}$, Amber Jaa-Kwee ${ }^{4}$ and Dorothy Bruck ${ }^{1}$

\section{Correction to: J Transl Med (2018) 16:24} https://doi.org/10.1186/s12967-018-1392-z The original version of this article [1], published on 6 February 2018, contains a mistake in the 'Conclusions' section. The corrected version of the affected sentence is given below and the corrected part is marked in bold.

- It is unclear whether the reduction in Streptococcus is particularly beneficial in some ME/CFS patients or whether other concurrent microbial shifts are equally or more valuable (i.e., increased Bacteroides and/or reduced Clostridium).

\section{Author details}

${ }^{1}$ Psychology Department, College of Health and Biomedicine, Victoria University, Melbourne, Australia. ${ }^{2}$ Bioscreen (Aust) Pty Ltd., Melbourne, Australia.

${ }^{3}$ CFS Discovery Clinic, Donvale, Melbourne, Australia. ${ }^{4}$ College of Engineering and Science, Victoria University, Melbourne, Australia.
The original article can be found online at https://doi.org/10.1186/ s12967-018-1392-z.

\section{Publisher's Note}

Springer Nature remains neutral with regard to jurisdictional claims in published maps and institutional affiliations.

Received: 14 February 2018 Accepted: 14 February 2018

Published online: 23 February 2018

\section{Reference}

1. Wallis A, Ball M, Butt $H$, Lewis DP, McKechnie S, Paull P, Jaa-Kwee A, Bruck D. Open-label pilot for treatment targeting gut dysbiosis in myalgic encephalomyelitis/chronic fatigue syndrome: neuropsychological symptoms and sex comparisons. J Transl Med. 2018;16:24. https://doi. org/10.1186/s12967-018-1392-z.

\footnotetext{
*Correspondence: Amy.Wallis@vu.edu.au

${ }^{1}$ Psychology Department, College of Health and Biomedicine, Victoria University, Melbourne, Australia

Full list of author information is available at the end of the article
} 